\title{
Diyabetlilerde Kendi Kendine Kan Şekeri İzlemi ile HbA1c ve Diyabet Komplikasyonlarının Karşılaştırılması
}

\author{
Comparison of Self-Monitoring Blood Glucose with HbA1c and Diabetes Complications in \\ Diabetics
}

\author{
Selda Çelik ${ }^{1}$, Cemile İdiz², Elif Bağdemir ${ }^{3}$, Sevim Purisa ${ }^{4}$, Nevin Dinççağ ${ }^{5}$, İlhan Satman ${ }^{6}$
}

Geliş tarihi/Received: 17.05.2018 • Kabul tarihi/Accepted: 30.07.2018

\section{ÖZET}

Amaç: Bu çalışma diabetes mellitus nedeniyle izlenen hastalarda kan şekeri ölçüm sıklığı ile diyabet regülasyonu ve diyabetin komplikasyonları arasındaki ilişkiyi belirlemek amacıyla yapılmıştır.

Bireyler ve Yöntem: Çalışma 951 diyabetli hastanın (tip1=90, tip2= 861) dosyalarının retrospektif olarak incelenmesi ile gerçekleştirilmiştir. Hastaların yaşı, cinsiyeti, boyu, ağırlı̆̆ı, diyabet tipi, diyabet süresi, diyabet tedavisi, hemoglobin A1c (HbA1c) değeri, nöropati varlığı, nefropati varlığı, diyabetik ayak varlığı, hipertansiyon varlığı, kan şekeri ölçüm sıklığı bilgileri not edilmiştir. Kan şekeri ölçüm sıklıklarına göre hastalar 3 gruba ayrılmıştır: haftada en az iki gün toplam 8 kez kan şekeri ölçümü yapanlar (grup 1), haftada iki günden az ve 8 ölçümden az kan şekeri ölçümü yapanlar (grup 2), düzensiz kan şekeri ölçümü yapmalarına rağmen doktor kontrolüne gelmeden önceki 2 gün içerisinde 8 kez kan şekeri ölçümü yapanlar (grup 3).

Bulgular: Hastaların 548'i kadın, 403’ü erkek, ortalama yaş 58.12 \pm 13.17 ylldır. Gruplar arasında HbA1c (p<0.001) ve diyabet süresi ( $<<0.001)$ parametrelerinde anlamlı fark belirlenmiştir. Hastaların kan şekeri ölçüm sıklığı ile diyabet tipi ( $<<0.001)$, diyabet tedavi şekli $(p<0.001)$, retinopati varlığı $(p<0.001)$, nefropati varlığı $(p<0.001)$, hipertansiyon varlığı $(p<0.001)$ arasında anlamlı bir fark olduğu saptanmıştır.

Sonuç: Doğru ölçüm tekniği ve güvenilir kan şekeri ölçüm aletleri ile yapılan kan şekeri ölçümü, hastanın diyabeti tanıması ve yönetmesine imkân tanımakla birlikte diyabete bağlı gelişebilecek komplikasyonların önüne geçilmesinde yardımcı olmaktadır.

Anahtar kelimeler: Diyabet, kan şekeri ölçümü, komplikasyon

\section{ABSTRACT}

Aim: This study aimed to determine the relationship between the frequency of measuring blood glucose levels and the complications and regulation of diabetes in patients under follow-up due to diabetes mellitus.

1. İletişim/Correspondence: Sağllk Bilimleri Üniversitesi, Hemşirelik Fakültesi, İstanbul, Türkiye • E-posta: seldacelik40@gmail.com

(1) https://orcid.org/0000-0003-4328-3189

2. İstanbul Üniversitesi, İstanbul Tıp Fakültesi, Endokrinoloji ve Metabolizma Hastalıkları Bilim Dalı, İstanbul, Türkiye (ㄱ) https://orcid.org/0000-0001-6635-5996

3. İstanbul Üniversitesi, İstanbul Tip Fakültesi, Endokrinoloji ve Metabolizma Hastalıkları Bilim Dalı, İstanbul, Türkiye (1) https://orcid.org/0000-0002-0035-6360
4. İstanbul Üniversitesi, Eczacllı Fakültesi, Farmasötik Teknoloji, İstanbul, Türkiye 으 https://orcid.org/0000-0002-2585-485X

5. İstanbul Üniversitesi, İstanbul Tip Fakültesi, Endokrinoloji ve Metabolizma Hastalıkları Bilim Dalı, İstanbul, Türkiye 으 https://orcid.org/0000-0003-3986-4546

6. İstanbul Üniversitesi, İstanbul Tip Fakültesi, Endokrinoloji ve Metabolizma Hastalıkları Bilim Dalı, İstanbul, Türkiye 으 https://orcid.org/0000-0001-8613-1797 
Subjects and Method: This study was conducted via retrospective evaluation of patient files of 951 diabetics (90 with type 1 diabetes and 861 with type 2 diabetes). Patient information including age, gender, height, weight, type of diabetes, duration of diabetes, treatment of diabetes, hemoglobin A1c (HbA1c) value, presence of neuropathy, presence of nephropathy, presence of diabetic foot, presence of hypertension, and frequency of measuring blood glucose levels were recorded. Patients were divided into 3 groups by the frequency of measuring blood glucose levels, where those who measured blood glucose levels a total of 8 times for at least two days a week were assigned to group 1, those who measured blood glucose levels less than 8 times for less than two days a week were assigned to group 2, and those who measured blood glucose levels 8 times in the 2 days prior to the control visit, who had previously measured blood glucose levels in an irregular manner were assigned to group 3.

Results: Of the patients, 548 were females and 403 were males, with a mean age of $58.12 \pm 13.17$ years. There was a significant difference in the parameters of HbA1c $(p<0.001)$ and the duration of diabetes $(p<0.001)$ between the groups. There was a significant difference between the frequency of measuring blood glucose levels and type of diabetes $(p<0.001)$, treatment of diabetes ( $p<0.001)$, presence of retinopathy ( $<0.001)$, presence of nephropathy $(p<0.001)$ and presence of hypertension $(\mathrm{p}<0.001)$.

Conclusion: Using accurate measurement techniques and reliable glucometers, blood glucose measurement allows patients to diagnose and manage diabetes, as well as helps to prevent the complications associated with diabetes.

Keywords: Diabetes, blood glucose measurement, complication

\section{GíRiş}

Diyabet, görülme sıklı̆̆ı hızla artan kronik seyirli endokrin ve metabolik bir hastalıktır (1-3). Tip 1 diyabet genellikle 30 yaş altında ortaya çıkmakta, tüm diyabetlilerin yaklaşık \%5-10'unu oluşturmakta ve her yıl yeni tanı konulan vaka sayısının 70.000 olduğu tahmin edilmektedir. Tip 1 diyabet insidansı 100.000'de 5-40 arasında değişmektedir (4-7). Tip 2 diyabet ise, erişkin toplumda en yaygın görülen metabolizma hastalığıdır. Yaşam tarzından kaynaklanan düzensiz ve dengesiz beslenme, fiziksel aktivite azlığı, sedanter yaşam ve stres gibi etmenlerin tip 2 diyabetin ortaya çıkışını hızlandırdığı bilinmektedir (5,8-10). Diyabet prevalansının 20-79 yaş arası bireylerde endişe verici şekilde artacağı, 2035 yılında 592 milyon kişinin (11), 2045 yllında ise 629 milyon bireyin diyabetten etkileneceği öngörülmektedir (5).

Diabetes mellitus tedavisinde medikal tedavi kadar hasta davranışlarını değiştirmek de önemlidir (12). Hastaların diyabetin kontrolünde kendi kendilerine yapacakları davranışsal yaklaşımlar içerisinde kan şekeri ölçümü en önemlilerinden biridir (13). Amerikan Diyabet Birliği (ADA), kendi kendine kan şekeri izleminin (self-monitoring of blood glucose,
$S M B G$ ), diyabetli hastalarda glisemik kontrolün sağlanmasında yardımcı olabileceğini belirtmektedir. Kendi kendine kan şekeri izlemi, diyabetlilerde uygulanan tedavinin etkisini ve glisemik hedeflere ulaşılma durumunu değerlendirmeye olanak sağlar. Ayrıca insülin kullanan hastaların izleminde, asemptomatik hipoglisemi ve hipergliseminin önlenmesinde önemli yer tutar (14). Glisemik değişkenlik eğilimi olan hastalar için glisemik kontrol SMBG sonuçlarının yorumlanmasıyla değerlendirilir (15). Evde kan şekeri izlemi hastaya ve doktora tedavinin ayarlanması ve daha iyi diyabet kontrolünün sağlanması için olanak tanır (16). Ayrıca diyabete bağlı ölümlerin en önemli nedeni olan kronik komplikasyonların, kan şekeri kontrolünün sağlanmasıyla uzun dönemde azaldığı görülmüştür (17).

Tip 1 diyabet ile yaplan Diyabet Kontrolü ve Komplikasyonları Çalışması (The Diabetes Control and Complications Trial-DCCT) ile Stockholm Diyabet Önleme Çalışması (The Stockholm Diabetes Intervention Study-SDIS) ve tip 2 diyabet ile ilgili yapılan İngiltere Prospektif Diyabet Çalışması 
(United Kingdom Prospective Diabetes Trial-UKPDS) ve Kumamoto Çalışması gibi çalışmalar göstermiştir ki glisemik kontrolün sağlanması diyabete bağlı gelişecek komplikasyonları geciktirebilmektedir (1720).

$\mathrm{Bu}$ çalışmanın amacı, diabetes mellitus nedeniyle izlenen hastalarda kan şekeri ölçüm sıklığı ile diyabet regülasyonu ve diyabet komplikasyonlarının karşılaştırılmasıdır.

\section{BİREYLER VE YÖNTEM}

Çalışmaya Haziran 2016- Nisan 2017 tarihleri arasında İstanbul Üniversitesi Tıp Fakültesi, İç Hastalıkları Anabilim Dalı, Endokrinoloji ve Metabolizma Hastalıkları Bilim Dalı Diyabet Polikliniği’ne başvuran 18yaşüstü toplam 951 hasta dahil edilmiştir. Hastaların dosyaları retrospektif olarak taranarak dosyalardan hastaların yaşı, cinsiyeti, boyu, ağırlı̆̆ı, diyabet tipi, diyabet süresi, aldığı diyabet tedavisi, son HbA1c kan değerleri, nöropati varlığı, nefropati varlığı, diyabetik ayak varlığı, hipertansiyon varlığı, kan şekeri ölçüm sıklığı bilgilerine ulaşılmıştır. Hastaların diyabet tanısı ve komplikasyonlarının tanıları ADA kılavuzu esas alınarak konulmuştur $(21,22)$.

Hastalar kan şekeri ölçüm sıklıklarına göre 3 gruba ayrılmıştır. İlk gruptaki hastalar haftada en az iki gün, toplam 8 kez kan şekeri ölçümü yapanlar olup bu grup düzenli kan şekeri ölçümü yapan grup olarak adlandırılmıştır. İkinci gruptaki hastalar haftada iki günden az ve 8 ölçümden az kan şekeri ölçümü yapanlar olup bu grup düzensiz kan şekeri ölçümü yapan grup olarak adlandırılmıştır. Üçüncü gruptaki hastalar ise düzensiz kan şekeri ölçümü yapmalarına rağmen doktor kontrolüne gelmeden önceki 2 gün içerisinde $8 \mathrm{kez}$ kan şekeri ölçümü yapanlar olarak belirlenmiştir. Hastaların dosyalarından ulaşılan veriler not edilerek gruplar arasında karşılaştırmalı olarak değerlendirilmiştir.

Çalışma için İstanbul Üniversitesi Etik Kurul onayı alınmıştır (Etik no: 2016/410). Çalışma, hastaların dosyaları retrospektif olarak taranarak gerçekleştirildiği için onam formu alınmamıştır.

\section{İstatistiksel Analiz}

Normallik denetimi tek örneklem Kolmogorov Smirnov testi, histogram, Q-Q plot ve box plot grafikleri çizilerek yapılmıştır. Normal dağılmayan değişkenlere dönüşüm (transformation) yapılarak normallik sağlanmaya çalışılmıştır. Veriler ortalama $(\overline{\mathrm{X}})$, standart sapma (S), frekans ve yüzde şeklinde verilmiştir. Gruplar arasında yaş, boy, beden kütle indeksi (BKI), HbA1c ve diyabet süresinin değerlendirmeleri Tek Yönlü Varyans Analizi (OneWay ANOVA) ile yapılmıştır. Nominal değişkenlerin gruplar arasında kıyaslamaları ise Ki-kare (Pearson Chi-Square) testi ile yapılmıştır. Anlamlılık sinırı $\mathrm{p}<0.05$ ve çift yönlü olarak alınmıştır. Analizler IBM SPSS Statistics 21.0 istatistik paket programı kullanılarak yapılmıştır.

\section{BULGULAR}

Çalışmaya katılan 951 hastanın 548'ikadın, 403'ü erkek, ortalama yaşı $58.12 \pm 13.17$ yll olup hastaların 90'ı tip 1 diyabetli, 861' $i$ ise tip 2 diyabetlidir. Çalışma grubunun diyabet süresi $13.39 \pm 8.02$ yll iken boy, ağırlık ve BKI ortalamaları sirasıyla $161.94 \pm 9.94 \mathrm{~cm}, 79.5 \pm 14.52 \mathrm{~kg}$ ve $30.44 \pm 5.70 \mathrm{~kg} / \mathrm{m}^{2}$ dir. Diyabet tedavisi için 28 hasta sadece diyet, 378 hasta sadece oral anti diyabetik ilaç (OAD), 123 hasta sadece insülin, 422 hasta ise hem OAD hem de insülin tedavisi uygulamaktadır. Çalışmaya katılan hastalarda görülen kronik komplikasyon oranları değerlendirildiğinde katılımcılarda saptanan retinopati, nefropati, nöropati ve diyabetik ayak oranları sırasıyla \%15.4, \%7, \%30.5 ve \%0.4’tür. Ayrıca katılımcıların \%31.3’ünde hipertansiyon saptanmıştır.

Hastaların kan şekeri ölçüm sıklığına bakıldığında 437 (\%46) hastanın düzenli aralıklarla kan şekeri ölçümü yaptığı (grup 1), 196 (\%20.6) hastanın düzensiz aralıklarla kan şekeri ölçümü yaptığı (grup 2), 318 (\%33.4) hastanın ise profil ve düzensiz aralıklarla kan şekeri ölçümü yaptığı (grup 3) görülmektedir.

Hastaların yaş, boy, diyabet süresi, BKİ ve HbA1c 
değerleri gruplar arasında karşılaştırıldığı zaman HbA1c ve diyabet süresi parametrelerinde gruplar arası farklılık gözlenmiştir $(p<0.001) \quad$ (Tablo 1). $\mathrm{Bu}$ farklılığın hangi gruplardan kaynaklandığına bakıldığında ise HbA1c parametresinde grup 1 ile grup 2 arasinda ve grup 1 ile grup 3 arasinda istatistiksel olarak anlamlı farklılık olduğu göze çarpmaktadır $(\mathrm{p}<0.001)$.

Tablo 1. Gruplar arasında yaş, boy, BKİ, HbA1c ve diyabet süresi parametrelerinin karşılaştırılması

\begin{tabular}{|c|c|c|c|c|}
\hline & $\begin{array}{c}\text { Grup } \frac{1}{\bar{X}_{ \pm}(n=437)} \\
\end{array}$ & $\begin{array}{c}\text { Grup } 2(n=196) \\
\bar{X}_{ \pm} S\end{array}$ & $\begin{array}{c}\text { Grup } 3(n=318) \\
\bar{X}_{ \pm} S\end{array}$ & $\mathbf{p}^{*}$ \\
\hline Yaş (yıl) & $57.91 \pm 13.81$ & $58.85 \pm 11.87$ & $57.95 \pm 13.07$ & 0.567 \\
\hline Boy $(\mathrm{cm})$ & $162.25 \pm 9.68$ & $162.29 \pm 10.30$ & $161.29 \pm 10.09$ & 0.363 \\
\hline BKİ $\left(\mathrm{kg} / \mathrm{m}^{2}\right)$ & $30.72 \pm 5.87$ & $30.37 \pm 5.23$ & $30.72 \pm 5.76$ & 0.564 \\
\hline HbA1c (\%) & $7.22 \pm 1.62$ & $7.78 \pm 1.52$ & $7.58 \pm 1.61$ & $\mathrm{p}<0.001$ \\
\hline $\begin{array}{l}\text { Diyabet } \\
\text { süresi (yll) }\end{array}$ & $14.75 \pm 8.16$ & $11.82 \pm 7.34$ & $12.50 \pm 7.95$ & $\mathrm{p}<0.001$ \\
\hline
\end{tabular}

BKİ: beden kütle indeksi, HbA1c: hemoglobin A1c

*Tek yönlü varyans analizi

Hastaların kan şekeri ölçüm sıklıkları ile cinsiyet, ölçüm sıklığı ile diyabet tipi, diyabet tedavi şekli, diyabet tipi, diyabet tedavi şekli, retinopati varlığı, nefropati varlığı, nöropati varlığı, diyabetik ayak varlığı ve hipertansiyon varlığı açısından gruplar arasında değerlendirme yapıldığında kan şekeri $(\mathrm{p}<0.001)($ Tablo 2-4).

Tablo 2. Kronik komplikasyonlar ve hipertansiyon ile kan şekeri ölçüm sıklığının karşılaştırılması

\begin{tabular}{lccccccc}
\hline \multirow{2}{*}{$\begin{array}{l}\text { Komplikasyon } \\
\text { varlığ }\end{array}$} & \multicolumn{2}{c}{ Grup 1, n (\%) } & \multicolumn{2}{c}{ Grup 2, n (\%) } & \multicolumn{2}{c}{ Grup 2, n (\%) } & \multirow{2}{*}{$\mathbf{p}^{*}$} \\
\cline { 2 - 6 } & Var & Yok & Var & Yok & Var & Yok & \\
\hline Retinopati & $85(8.9)$ & $352(37)$ & $22(2.3)$ & $174(18.3)$ & $39(4.1)$ & $179(29.3)$ & $\mathrm{p}<0.001$ \\
Nefropati & $41(4.3)$ & $396(41.6)$ & $9(0.9)$ & $187(19.7)$ & $17(1.8)$ & $301(31.7)$ & $\mathrm{p}<0.001$ \\
Nöropati & $142(14.9)$ & $295(31)$ & $53(5.6)$ & $143(15)$ & $95(10)$ & $223(23.4)$ & 0.371 \\
Diyabetik ayak & $2(0.2)$ & $435(45.7)$ & $1(0.1)$ & $195(20.5)$ & $1(0.1)$ & $317(33.3)$ & 0.934 \\
Hipertansiyon & $129(13.6)$ & $308(32.4)$ & $32(3.4)$ & $164(17.2)$ & $137(14.4)$ & $181(19)$ & $\mathrm{p}<0.001$ \\
\hline
\end{tabular}

*Ki kare test

Tablo 3. Diyabet tipi ile kan şekeri ölçüm sıklığının karşılaştırılması

\begin{tabular}{lcccc}
\hline Diyabet tipi & $\begin{array}{c}\text { Grup 1 } \\
\text { n (\%) }\end{array}$ & $\begin{array}{c}\text { Grup 2 } \\
\text { n (\%) }\end{array}$ & $\begin{array}{c}\text { Grup 3 } \\
\text { n (\%) }\end{array}$ & p* \\
\hline Tip 1 diyabet & $62(68.89)$ & $7(7.78)$ & $21(23.33)$ & $<0.001$ \\
Tip 2 diyabet & $375(43.55)$ & $189(21.95)$ & $297(34.49)$ & \\
\hline *Ki kare test & & & &
\end{tabular}

Tablo 4. Diyabet tedavi şekli ile kan şekeri ölçüm sıklığı sıklığının karşılaştırılması

\begin{tabular}{|c|c|c|c|c|}
\hline & \multicolumn{4}{|c|}{ Diyabet tedavi şekli } \\
\hline & Diyet & OAD & $\begin{array}{c}\text { Insülin + } \\
\text { OAD }\end{array}$ & İnsülin \\
\hline Grup 1, n (\%) & $4(0.92)$ & $114(26.09)$ & $238(54.46)$ & $81(18.53)$ \\
\hline Grup 2, n (\%) & $16(8.16)$ & $121(61.73)$ & $45(22.96)$ & $14(7.14)$ \\
\hline Grup 3, n (\%) & $8(2.52)$ & 143 (44.97) & 139 (43.71) & $28(8.80)$ \\
\hline$\underline{\mathbf{p}^{*}}$ & \multicolumn{4}{|c|}{$<0.001$} \\
\hline
\end{tabular}




\section{TARTIŞMA}

İnsülin kullansın veya kullanmasın yapilan birçok çalışmada ve kılavuzlarda tüm diyabetli hastalarda SMBG uygulaması önerilmektedir $(14,23-$ 27). Hastaların diyabetin tedavisi ve kontrolü için eğitilmesi ve desteklenmesinin akut ve uzun dönem komplikasyonları azalttığı düşünülmektedir (28). Hastaların ve sağlık görevlilerinin diyabet yönetiminde glisemik kontrolün etkinliğini değerlendirmek için iki primer tekniği bulunmaktadır. Bunlardan biriSMBG, diğeri ise HbA1c'dir (14). Diyabet tedavisi konusunda en önemli kllavuzlarından biri olan ADA kllavuzu, çoklu insülin dozu uygulayan veya insülin pompası kullanan diyabetli hastaların ara öğün veya yemeklerden hemen önce, ara ara yemeklerden sonra, yatmadan önce, egzersizden önce, kan şekerlerinin düştüğünü düşündükleri zaman, düşük kan şekeri nedeniyle tedavi alırken kan şekerleri normal olana kadar, araba kullanma gibi kritik işlerden önce kan şekeri ölçümü yapmaları gerektiğini belirtmektedir (14).

Tip 1 diyabetliler ile yapılan çalışmalarda sıkı glisemik kontrolün ve yoğun insülin tedavisinin diyabetin mikrovasküler komplikasyonlarının oluşumunu geciktirdiği ve ilerlemesini yavaşlattığı, kardiyovasküler hastalık riski üzerinde uzun vadede yararlı etkileri olduğu saptanmıştır $(17,29)$. Yoğun insülin tedavisinin en önemli parametrelerinden biri olan SMBG, kan şekerine göre insülin dozlarının ayarlanmasina, hiperglisemi ve hipogliseminin oluşmasının engellenmesine yardımcı olmaktadır $(12,14,15)$.

Daha sık kan şekeri ölçümü yapan hastaların HbA1c düzeyleri daha düşük olmaktadır (25). Tip 2 diyabetli 94 hasta üzerinde yapılan bir çalışmada, evde kendi kendine kan şekeri izlenme sıklığı ile HbA1c değerleri karşılaştırılmıştır (30). Hastalar kan şekeri ölçüm sıklıklarına göre günlük, haftalık, aylık kan şekeri ölçenler ve hiç kan şekeri ölçümü yapmayanlar olarak 4 gruba ayrılmış, her gün düzenli kan şekeri ölçümü yapan hastaların, haftalık, aylık kan şekeri ölçümü yapanlar ile hiç kan şekeri ölçümü yapmayan hastalara göre HbA1c değerleri istatistiksel olarak anlamlı oranda düşük bulunmuştur $(p<0.01)$. En az 1 ylldir tip 1 diyabeti olan ve SBMG uygulanmayan 20,555 hastanın değerlendirdiği bir diğer çalışmada ise günlük kan şekeri ölçüm sayısının artması ile HbA1c değerlerinin orantılı olarak azaldığı ve daha iyi glisemik kontrol sağlandığı gösterilmiştir (31).

Günlük olarak iki kereden fazla insülin enjeksiyonu uygulayan bireyler, günde en az üç kez SMBG yapmalıdır (32). Oysaki kan şekeri ölçüm sıklığının arttırılması yönündeki kanıtlara rağmen diyabetli hastaların kan şekeri ölçümü için kullanacağı ölçüm çubuğu sayısı sinırlı tutulabilmektedir (31). Kendi kendine kan şekeri izleminin ekonomik yönü sıklıkla ihmal edilen önemli bir konudur (33). Ülkemizde, kılavuzlara uygun şekilde ölçüm çubuğu sağlanmaktadır. Sosyal Güvenlik Kurumu Sağlık Uygulama Tebliği'ne göre kan şekeri ölçüm çubuklarının, tip 1 diyabetli erişkin hastalar ve insülin kullanan tip 2 diyabetli tüm hastalarda ayda en fazla 150 adet, OAD kullanan diyabetli hastalara 3 ayda en fazla 100 adet hesabıyla reçete edilmesi halinde bedeli kurumca karşılanmaktadır (34). Miller ve arkadaşlarının (31) çalışmasında bazı ülkelerdeki ölçüm çubuğu kısıtlamalarına bağlı sağlık harcamalarını azaltmaya çalışmanın, diyabete bağlı oluşabilecek komplikasyonlar nedeniyle efektif sonuçlar doğurmayacağı belirtilmektedir. Ancak 657 tip 2 diyabetli hastanın kan şekeri ölçüm sıklığı ve ölçüm çubuğu maliyetinin değerlendirildiği başka bir çalışmada ölçüm çubuğu kullanım oranları en az OAD, ardından OAD ve insülin kullananlar, en fazla ise insülin kullananlar olarak bulunmuştur. Ayrica OAD ile monoterapi ya da OAD ile kombine tedavi alan gruplarda kullanılan ölçüm çubuğu sayısı ile HbA1c hedefine ulaşan hasta sayıları arasında anlamlı ilişki saptanırken, insülin kullanan hastalarda böyle bir ilişki gözlenmemiştir (35). Bu çalışmanın sonuçlarında da düzenli kan şekeri ölçen hastaların HbA1c değerleri düzensiz kan şekeri ölçenlere göre anlamlı oranda düşük olduğu göze çarpmaktadır. 
Kendi kendine kan şekeri izlemi her ne kadar önemli olsa da ölçüm aletlerinin kullanımına bağlı hatalar, çevresel etmenlerin etkisi (aşırısoğuk, aşırısıcak hava), hematokrit değerlerinin çok fazla olması, hastaların diğer hastalıklar için kullandığı ilaçlar kan şekeri ölçümlerinde yanlış okumalara neden olabilmektedir. Kan şekerinin yanlış ölçülmesi, insülin dozlarının yanlış uygulanmasına, bu da hipoglisemi veya hiperglisemi oluşmasına zemin hazırlayabilmektedir. $\mathrm{Bu}$ gibi yanlışlıklara neden olmamak için hasta eğitimi konusunda bilgili bir diyabet yönetim ekibi tarafindan yapılması gerekmektedir (36).

$\mathrm{Bu}$ çalışmanın sonuçları bize göstermektedir ki tip 1 diyabetliler, diyabet tedavisi için insülin kullananlar, retinopati gelişmiş olan hastalar ve nefropati gelişmiş olan hastalar daha düzenli kan şekeri ölçümü yapmaktadırlar. Ayrıca hipertansiyon gelişmemiş hastaların daha düzensiz kan şekeri ölçümü yaptığı göze çarpmaktadır.

Diyabet tedavisinde düzenli ve önerilen şekilde yapılan kan şekeri ölçümleri, hem hastanın diyabeti tanıması ve yönetmesine imkân tanımakta, hem de diyabete bağlı gelişebilecek komplikasyonların önüne geçilmesinde yardımcı olmaktadır.

Çıkar çatışması - Conflict of interest: Yazarlar çıkar çatışması olmadığını beyan ederler. - The authors declare that they have no conflict of interest.

\section{KAYNAKLAR}

1. American Diabetes Association. Standards of medical care in diabetes. Diabetes Care 2017;40(1):1-135.

2. Bennet PH, Knowler WC. Definition, Diagnosis and Classification of Diabetes Mellitus and Glucose Homeostaisis. In: Kahn CR, Weir GC, King GL, Jacobson AM, Moses AC, Smith RJ, editors. Joslin Diabetes Mellitus. 14th ed. Lippincott Williams \&Wilkins; 2005.p.331-39.

3. Türkiye Endokrinoloji ve Metabolizma Derneği (TEMD) Diabetes Mellitus Çalışma ve Eğitim Grupları. Diabetes Mellitus ve Komplikasyonlarının Tanı Tedavi ve İzlem Kılavuzu. İstanbul, Türkiye Endokrinoloji ve Metabolizma Derneği. 2017, Ankara.

4. Dinççă̆ N. Tip 1 Diyabetin Epidemiyolojisi. Diyabet El Kitabi. İstanbul Tip Kitabevi; 2013. s. 35-43.

5. International Diabetes Federation. Diabetes Atlas. 8th ed. 2017. Available at: http://diabetesatlas.org/ resources/2017-atlas.html.

6. Yılmaz T. Tip 1 diabetes mellitus. İmamoğlu Ş, Ersoy C, editörler. Diabetes Mellitus. 3. baskı. Deomed Medikal Yayıncılık; İstanbul, 2009. s. 38-51.

7. American Diabetes Association. Standards of medical care in diabetes. Diabetes Care 2013;36(1):11-66.

8. Örük G, Çömlekçi A. Diabetes Mellitus Tedavisinde Genel Yaklaşım. Kahn CR, Weir GC, King GL, Jacobson AM, Moses AC, Smith RJ, editörler. Yumuk V, çeviri editörü. Joslin's Diabetes Mellitus. 1. baskı. İstanbul Medikal Yayıncılık, İstanbul; 2008. s.587-596.

9. Kabalak T, Çetinkalp Ş. Tip 2 diabetes mellitus. İmamoğlu §̧, Ersoy C, editörler. Diabetes Mellitus. 3. baskı. Deomed Medickal Yayıncılık, İstanbul; 2009. s. 54-72.

10. Satman I, Omer B, Tutuncu Y, Kalaca S, Gedik S, Dinccag $\mathrm{N}$, et al. Twelve-year trends in the prevalence and risk factors of diabetes. Eur J Epidemiol 2013;28:169-80.

11. Guariguata L, Whiting DR, Hambleton I, Beagley J, Linnenkamp U, Shaw JE. Global estimates of diabetes prevalence for 2013 and projections for 2035. Diabetes Res Clin Pract 2014;103:137-49.

12. American Diabetes Association. Approaches to glycemic treatment. Diabetes Care 2016;39(1):52-59.

13. Helgeson VS, Honcharuk E, Becker D, Escobar O, Siminerio L. A focus on blood glucose monitoring: relation to glycemic control and determinants of frequency. Pediatr Diabetes 2011;12(1):25-30.

14. American Diabetes Association. Glycemic Targets. Diabetes Care 2016;39(1):39-46.

15. Silver B, Ramaiya K, Andrew SB, Fredrick O, Bajaj S, Kalra S, et al. EADSG Guidelines: Insulin Therapy in Diabetes. Diabetes Ther 2018;9(2):449-492.

16. McCall AL, Mullin CJ. Home monitoring of diabetes mellitus--a quiet revolution. Clin Lab Med 1986;6(2):215239.

17. The Diabetes Control and Complications Trial Research Group. The effect of intensive treatment of diabetes on the development and progression of long-term complications in insulin-dependent diabetes mellitus. N Eng J Med 1993;329:977-986.

18. Reichard P, Berglund B, Britz A, Cars I, Nilsson BY, Rosenqvist U. Intensified conventional insulin treatment retards the microvascular complications of insulindependent diabetes mellitus (IDDM): the Stockholm Diabetes Intervention Study (SDIS) after 5 years. J Intern Med 1991;230:101-108.

19. Turner RC, Cull CA, Frighi V, Holman RR. Glycemic control with diet, sulfonylurea, metformin, or insulin in patients with type 2 diabetes mellitus: progressive requirement for multiple therapies (UKPDS 49). UK 
Prospective Diabetes Study (UKPDS) Group. JAMA 1999;281:2005-2012.

20. Shichiri M, Kishikawa H, Ohkubo Y, Wake N. Long-term results of the Kumamoto Study on optimal diabetes control in type 2 diabetic patients. Diabetes Care 2000;23 (2):21-29.

21. American Diabetes Association. Cardiovascular Disease and Risk Management. Diabetes Care 2016;39(1):60-71.

22. American Diabetes Association. Microvascular Complications and Foot Care. Diabetes Care 2016;39(1):72-80.

23. Durán A, Martín P, Runkle I, Pérez N, Abad R, Fernández $\mathrm{M}$, et al. Benefits of self-monitoring blood glucose in the management of new-onset type 2 diabetes mellitus: the St Carlos Study, a prospective randomized clinic based interventional study with parallel groups. J Diabetes 2010;2:203-211.

24. Schnell O, Alawi H, Battelino T, Ceriello A, Diem P, Felton AM, et al. Self-monitoring of blood glucose in type 2 diabetes: recent studies. J Diabetes Sci Technol 2013;7:478-488.

25. Polonsky WH, Fisher L, Schikman CH, Hinnen DA, Parkin CG, Jelsovsky Z, et al. Structured self monitoring of blood glucose significantly reduces $\mathrm{A} 1 \mathrm{C}$ levels in poorly controlled, noninsulin-treated type 2 diabetes: results from the Structured Testing Program study. Diabetes Care 2011;34:262-267.

26. Klonoff DC, Blonde L, Cembrowski G, Chacra AR, Charpentier G, Colagiuri S, et al. Consensus report: the current role of self-monitoring of blood glucose in noninsulin-treated type 2 diabetes. J Diabetes Sci Technol 2011;5:1529-1548.

27. Ryden L, Grant PJ, Anker SD, Berne C, Cosentino F, Danchin N, et al. ESC guidelines on diabetes, pre-diabetes, and cardiovascular diseases developed in collaboration with the EASD: the Task Force on diabetes, prediabetes, and cardiovascular diseases of the European Society of Cardiology (ESC) and developed in collaboration with the European Association for the Study of Diabetes (EASD). Eur Heart J 2013;34:3035-3087.
28. American Diabetes Association. Introduction. Diabetes Care 2016;39 (1):1-2.

29. Nathan DM, Cleary PA, Backlund JY, Genuth SM, Lachin JM, Orchard TJ, et al. Diabetes Control and Complications Trial/Epidemiology of Diabetes Interventions and Complications (DCCT/EDIC) Study Research Group. Intensive diabetes treatment and cardiovascular disease in patients with type 1 diabetes. N Engl J Med 2005;353:2643-2653.

30. Ozgur R, Mavis O, Ayalp P. Tip 2 diabetes mellituslu hastalarda evde glukoz takibi sıklığı ve HbA1c ile ilişkisi. Okmeydanı Tıp Dergisi 2011;27(2):70-75.

31. Miller KM, Beck RW, Bergenstal RM, Goland RS, Haller MJ, McGill JB, et al. T1D Exchange Clinic Network. Evidence of a strong association between frequency of self-monitoring of blood glucose and hemoglobinA1c levels in T1D exchange clinic registry participants. Diabetes Care 2013;36(7):2009-2014.

32. Murata GH, Shah JH, Hoffman RM, Wendel CS, Adam KD, Solvas PA, et al. Intensified blood glucose monitoring improves glycemic control in stable, insulin-treated veterans with type 2 diabetes: the Diabetes Outcomes in Veterans Study (DOVES). Diabetes Care 2003;26(6):17591763.

33. Kim KS. Self-monitoring of blood glucose in patients with insulin-treated type 2 diabetes mellitus. Diabetes Metab J 2018;42(1):26-27.

34. Sosyal Güvenlik Kurumu Sağlık Uygulama Tebliği. 18 Şubat 2015. Erişim: http://istanbultip.istanbul. edu.tr/wp-content/uploads/2015/02/18-02-2015De\%C4\%9Fi\%C5\%9Fiklik-i\%C5\%9Flenmi\%C5\%9Fg\%C3\%BCncel-2013-SUT.pdf. Erişim tarihi: 3 Ocak 2017.

35. Elgart JF, González L, Prestes M4, Rucci E, Gagliardino JJ. Frequency of self-monitoring blood glucose and attainment of HbA1c target values. Acta Diabetol 2016;53(1):57-62.

36. Erbach M, Freckmann G, Hinzmann R, Kulzer B, Ziegler $\mathrm{R}$, Heinemann $\mathrm{L}$, et al. Interferences and limitations in blood glucose self-testing: An overview of the current knowledge. J Diabetes Sci Technol 2016;22(5):1161-1168. 